\title{
DESORDENS MUSCULOESQUELÉTICAS EM VIOLINISTAS E VIOLISTAS PROFISSIONAIS. REVISÃO SISTEMÁTICA
}

\author{
MUSCULOSKELETAL DISORDERS IN PROFESSIONAL VIOLINISTS AND VIOLISTS. SYSTEMATIC REVIEW
}

\author{
Geraldo Fabiano de Souza Moraes ${ }^{1}$, Adriana Papini Antunes ${ }^{1}$
}

\section{RESUMO}

Devido à alta demanda física e psicológica de trabalho, os músicos possuem grande risco de desenvolver uma variedade de problemas de saúde. As maiores causas de desordens musculoesqueléticas observadas em instrumentistas são excesso de uso, compressão nervosa e distonia focal. O objetivo deste artigo é identificar as desordens musculoesqueléticas que acometem com maior freqüência os violinistas e violistas profissionais. Foram lidos 50 artigos, desses, 24 foram utilizados. A escala PEDro foi utilizada para atestar a qualidade dos artigos. A definição dos fatores de risco pode ajudar na elaboração de programas de prevenção. Tocar instrumentos musicais envolve combinação de ações, incluindo movimentos rápidos, repetitivos e complicados das mãos e dedos. As cadeiras não oferecem outra opção senão a adaptação do corpo frente às exigências posturais. Para atingir destreza necessária para se tornar um músico de alto nível, são necessárias muitas horas de treinamento e aperfeiçoamento. O pescoço, ombro e a articulação temporomandibular são os mais afetados devido à posição prolongada de flexão da cabeça e ombro para segurar o violino, cotovelo e dedos também são alvos de desordens. É necessário alertar aos músicos de como são os sintomas iniciais para evitar que o distúrbio se agrave.

Nível de Evidência I, Centro de Medicina baseada em Evidência, Oxford, Reino Unido.

Descritores: Músculo esquelético/lesões. Doenças profissionais. Fatores de risco.

\section{ABSTRACT}

Due to the high physical and psychological demands of their work, musicians have a high risk of developing a range of health proble$m s$. The main causes of musculoskeletal disorders seen in instrumentalists are overuse, nerve compression and focal dystonia. The aim of this paper is to identify the musculoskeletal disorders that most frequently affect professional violinists and violists. 50 articles were read, of which 24 were used. The PEDro scale was used to determine the quality of the articles. The definition of risk factors can help in the development of prevention programs. Playing a musical instrument involves a combination of actions, including rapid, repetitive and complicated movements of the hands and fingers. The chairs used offer no other option than to adapt to the demands of body posture. To achieve the necessary skills to become a musician of a high standard, many hours of training and perfection are required. The neck, shoulder and temporomandibular joints are the most commonly affected areas, due to prolonged flexion of the head and shoulder required to hold the violin. The elbow and fingers are also common sites of disorders. It is necessary to warn musicians of the initial symptoms, and how they can prevent the disorder from worsening. Level I Evidence (Centre for Evidence-Based Medicine, Oxford, UK).

Keywords: Muscle, skeletal /injuries. Occupational diseases. Risk factors.
Citação: Moraes GFS, Papini AA. Desordens musculoesqueléticas em violinistas e violistas profissionais - revisão sistemática. Acta Ortop Bras. 2012;20(1):43-7. Disponível em URL: http://mww.scielo.br/aob.
Citation: Moraes GFS, Papini AA. Musculoskeletal disorders in professional violinists and violists - systematic review. Acta Ortop Bras. 2012;20(1):43-7. Available from URL: http://wuw.scielo.br/aob.

\section{INTRODUÇÃO}

Devido à alta demanda física e psicológica de trabalho, os músicos possuem grande risco de desenvolver uma variedade de problemas de saúde. Os músicos que tocam instrumentos de sopro podem ter estresse dental e aumento da pressão intra-ocular e os que tocam instrumentos de corda podem ter dermatites e desordens musculoesqueléticas. ${ }^{1}$
Violinistas e violistas comumente sofrem de distúrbios na mandíbula, costas, pescoço, ombro e mãos, esses distúrbios podem ser musculares ou nervosos. ${ }^{2}$ As desordens são causadas por repetitividade, posturas inadequadas e estresse causado por permanecer por tempo prolongado na posição sentada ou transportando instrumentos. ${ }^{3}$ As maiores causas de desordens musculoesqueléticas observadas em instrumentistas são excesso de uso (overuse),

Todos os autores declaram não haver nenhum potencial conflito de interesses referente a este artigo.

\section{1 - Universidade Federal de Itajubá Campus Itabira, MG. Brasil.}

Trabalho realizado na Universidade Federal de Itajubá - Campus Itabira.

Correspondência: Universidade Federal de Itajubá - Campus Itabira. Rua Irmã Ivone Drumond, no 200, Distrito Industrial II - Itabira, MG. Brasil. CEP: $35903-087$. E-mail: geraldmoraes@terra.com.br, 
compressão nervosa e distonia focal. ${ }^{3-5}$ Dor é o maior sintoma de lesões por overuse e músicos que tocam instrumentos de corda são os mais acometidos ${ }^{3}$.

Existem fatores intrínsecos e extrínsecos para essas desordens. A relação entre o músico e seus instrumentos é o foco de análise ergonômica e treino biomecânico, o alinhamento postural é essencial, levando a posições adequadas de pescoço e mãos. ${ }^{1}$

O trabalho dos violinistas e violistas requer uma posição sentada durante todo o período do ensaio e apresentação. Estes procuram o melhor posicionamento do corpo, buscando equilíbrio e distribuição do peso corporal para obter maior controle motor e precisão dos movimentos na execução instrumental. ${ }^{6}$ Este artigo justifica-se pela necessidade de identificar as principais desordens que acometem esses profissionais para que seja possível, posteriormente, a elaboração de planos preventivos.

O objetivo deste artigo é identificar as desordens musculoesqueléticas que acometem com maior frequência os violinistas e violistas profissionais.

\section{MATERIAIS E MÉTODO}

Foram utilizados artigos, teses e dissertações, buscados nas bases de dados, Medline, Lilacs, Cochrane e Scielo. As palavras chave utilizadas foram desordem musculoesquelética, lesões, músicos em português, inglês e espanhol. Foram selecionados somente artigos em português, inglês e espanhol, sem limite de data. A Tabela 1 fornece detalhes sobre a combinação de palavras-chave na busca nos bases de dados. Foi utilizada também busca manual de bibliografias em revistas, livros, por autores chave e informações relevantes.

\section{Critérios de inclusão e exclusão}

Foram incluídos estudos que mencionaram instrumentistas de corda, instrumentos de corda com arco, violinistas e violistas. Estudos que não relataram o tipo de músicos ou instrumentos utilizados foram excluídos. (Tabela 1)

\begin{tabular}{c|c|c}
\multicolumn{2}{c}{ Tabela 1. Resultados das Diferentes Bases de dados eletrônicas. } \\
\hline Base de dados & Palavras-chave & Resultados \\
\hline MEDLINE & $\begin{array}{c}\text { Músicos; lesões músicos; desordem } \\
\text { musculoesquelética; violinista; violista. }\end{array}$ & 394 \\
\hline LILACS & $\begin{array}{c}\text { Músicos; lesões músicos; desordem } \\
\text { musculoesquelética; violinista; violista. }\end{array}$ & 47 \\
\hline Cochrane & $\begin{array}{c}\text { Músicos; lesões músicos; desordem } \\
\text { musculoesquelética; violinista; violista. }\end{array}$ & 38 \\
\hline SCIELO & $\begin{array}{c}\text { Músicos; lesões músicos; desordem } \\
\text { musculoesquelética; violinista; violista. }\end{array}$ & 62 \\
\hline Total de citações & & 541 \\
\hline
\end{tabular}

\section{RESULTADOS}

Dos artigos encontrados pelas bases de dados e pela busca manual, 58 artigos foram potencialmente selecionados e lidos. Desses, 30 atenderam aos critérios de inclusão iniciais de foram utilizados. A Figura 1 detalha a busca. A escala PEDro foi utilizada para atestar a qualidade dos artigos. (Tabela 2)

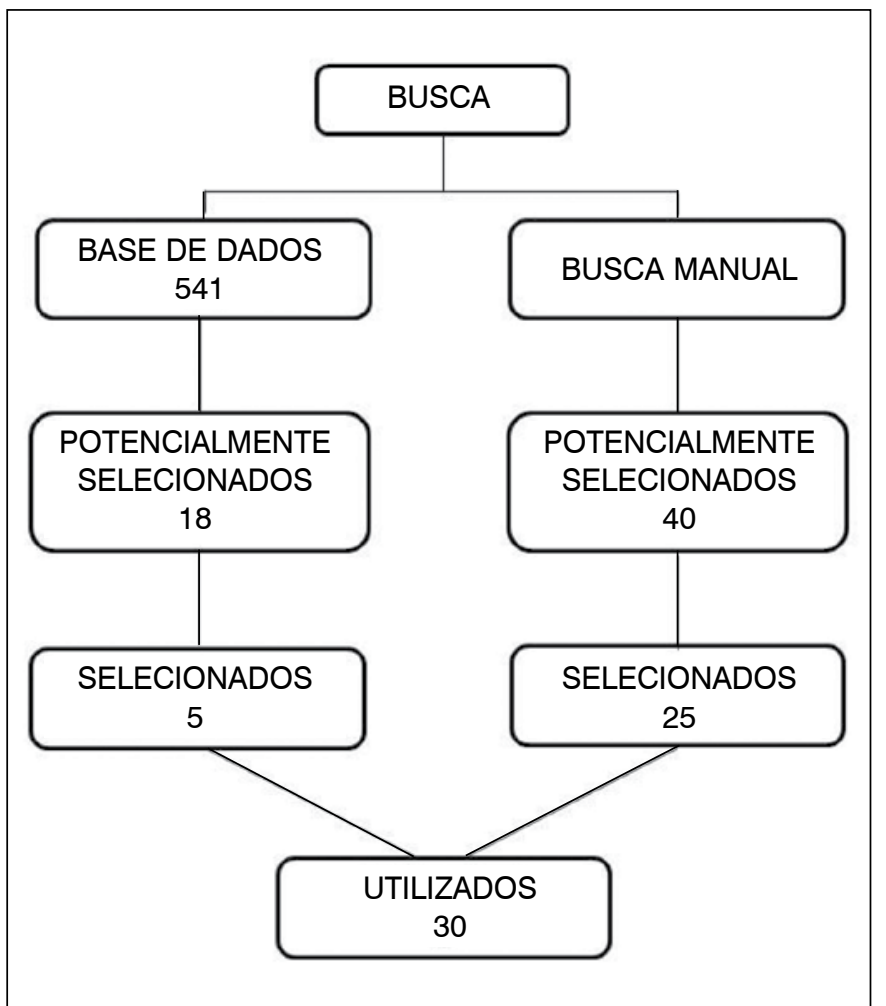

Figura 1. Resultado da busca.

\section{DISCUSSÃO}

Tocar instrumentos musicais envolve uma grande combinação de ações, incluindo movimentos rápidos, repetitivos e complicados das mãos e dedos. O que requer grande esforço dos músculos, ligamentos e ossos. ${ }^{7}$ De acordo com Foxman et al. ${ }^{1}$ e Lederman ${ }^{8}$, violinistas têm quatro vezes mais dor no antebraço direito. Hagberg et al. ${ }^{9}$ encontrou que violinistas têm duas vezes mais risco de dor no pescoço, ombro direito e antebraço esquerdo, quando comparados com pianistas.

Fry ${ }^{10}$ relata que os distúrbios musculoesqueléticos são comuns em músicos e se caracterizam por dor e tensão músculo-ligamentar, fraqueza muscular e perda do controle motor nos segmentos afetados.

Os problemas musculoesqueléticos mais observados em músicos são: excesso de uso (overuse) 50\%, compressão nervosa ou síndrome do desfiladeiro torácico $20 \%$, distonia focal $10 \%{ }^{1}$

Em seu estudo, Lederman ${ }^{8}$, observou que nos instrumentistas de corda, $69 \%$ tinham problemas musculoesqueléticos, 19\% nervo periférico, $5 \%$ distonia focal e $7 \%$ outros. Ostwald et al. ${ }^{11}$ e Hayden $^{12}$, constataram que $62 \%$ dos violinistas e violinistas sofrem de lesões submandibulares causados pela forma como eles apóiam os instrumentos.

Os sintomas inicias, que frequentemente, aparecem são dores, aproximadamente $85 \%$ dos casos, queimações, cansaço, membro pesado em uma ou mais partes do corpo e podem surgir mesmo após pouco tempo de atividade. ${ }^{5,8,11}$

A síntese da revisão bibliográfica determina, na maioria das vezes, que o fator responsável pela desordem musculoesquelético em músicos é biomecânico. Contudo acredita-se que outros aspectos devem ser considerados ao se apontarem os fatores determinantes dessas disfunções. 
Tabela 2. Descrição dos estudos.

\begin{tabular}{|c|c|c|c|c|}
\hline Estudo & População & Métodos & Resultados & $\begin{array}{l}\text { Escala } \\
\text { PEDro }\end{array}$ \\
\hline Fry H (1988) & $\begin{array}{l}\text { N: } 175 \text { Músicos } \\
\text { de } 9 \text { orquestras } \\
\text { sinfônicas e } 11 \\
\text { escolas }\end{array}$ & $\begin{array}{l}\text { Pacientes com oversuse grau 1e } 2 \text { foram } \\
\text { tratados conservadoramente. Os com grau } \\
\text { mais alto foram submetidos ao tratamento } \\
\text { radical de descanso. }\end{array}$ & $\begin{array}{l}\text { Violino: } 22 \text { tratados. Dos } 5 \text { tratados conservadoramente, } 4 \text { tiveram melhora. } \\
\text { Dos } 16 \text { tratados radicalmente, } 8 \text { foram curados. Viola: } 5 \text { tratados. Todos } 4 \\
\text { tratados conservadoramente foram curados. } 1 \text { foi tratado radicalmente e } \\
\text { apresentou melhora do quadro. }\end{array}$ & 3 \\
\hline $\begin{array}{l}\text { Zaza C, } \\
\text { Farewell V. } \\
(1997)\end{array}$ & $\begin{array}{l}281 \text { músicos } \\
\text { clássicos } \\
\text { profissionais e } \\
\text { estudantes da } \\
\text { universidade } \\
\text { de música de } \\
\text { Ontário }\end{array}$ & $\begin{array}{l}\text { Foram aplicados questionários e medidas } \\
\text { de hipermobilidade. }\end{array}$ & $\begin{array}{l}\text { Músicos de corda têm } 4 \mathrm{x} \text { mais probabilidade de desenvolver lesões } \\
\text { relacionadas à prática musical. Mulheres foram mais acometidas. }\end{array}$ & 5 \\
\hline Costa C (2003) & $\begin{array}{l}6 \text { violistas do } \\
\text { sexo masculino, } \\
\text { faixa etária } \\
\text { entre } 22 \text { e } 47 \\
\text { anos. }\end{array}$ & $\begin{array}{l}\text { Foram realizadas análise ergonômica } \\
\text { do trabalho, entrevistas individuais semi- } \\
\text { estruturadas e questionário impresso. }\end{array}$ & $\begin{array}{l}5 \text { dos } 6 \text { sujeitos sentiam dor relacionada ao tocar. Diagnósticos: tendinite, } \\
\text { problema postural, problema psicossomático e Lesão por Esforço Repetitivo } \\
\text { (L.E.R.). Tratamento: fisioterapia ( } 4 \text { casos) e acupuntura ( } 2 \text { casos). A } \\
\text { organização do trabalho lhes autoriza pouca margem de manobra para } \\
\text { minimizar a ocorrência de dor. }\end{array}$ & 1 \\
\hline $\begin{array}{l}\text { Hagberg M, } \\
\text { Thiringer G, } \\
\text { Brandstrom L. } \\
(2005)\end{array}$ & $\begin{array}{l}407 \text { estudantes } \\
\text { de música }\end{array}$ & Foi aplicado questionário & $\begin{array}{l}\text { Violinistas têm duas vezes mais risco de dor no pescoço, ombro direito } \\
\text { e antebraço esquerdo, quando comparados com pianistas. Violistas e } \\
\text { violinistas tem a incidência de dor no pescoço, ombro, cotovelo e antebraço } \\
\text { maior quando comparados com pianistas. }\end{array}$ & 2 \\
\hline $\begin{array}{l}\text { Foxman I, } \\
\text { Burgel B } \\
(2006)\end{array}$ & $\begin{array}{l}10 \text { músicos da } \\
\text { comunidade }\end{array}$ & $\begin{array}{l}\text { Responderam a um questionário sobre } \\
\text { fatores de risco e problemas relacionados } \\
\text { à músicos }\end{array}$ & $\begin{array}{l}9 \text { foram diagnosticados com desordem musculoesquelética; Principais } \\
\text { locais de dor foram: dedos, ombro e coluna; Apresentaram como fatores } \\
\text { de risco: tempo prolongado de prática, repetitivas habilidades finas com } \\
\text { as mãos, manter-se sentado por tempo prolongado, trabalhar em posição } \\
\text { desconfortável. }\end{array}$ & 2 \\
\hline $\begin{array}{l}\text { Abréu-Ramos } \\
\text { A, Micheo W } \\
(2007)\end{array}$ & $\begin{array}{l}75 \text { músicos } \\
\text { da Orquestra } \\
\text { Sinfônica de } \\
\text { Porto Rico }\end{array}$ & $\begin{array}{l}\text { Questionário e avaliação } \\
\text { neuromusculoesquelética }\end{array}$ & $\begin{array}{l}81,3 \% \text { relataram desordens musculoesqueléticas. Destes, } 83,6 \% \text { relataram } \\
\text { correlação com a prática. Dor lombar foi citada por } 75,4 \% \text {. Violinistas e } \\
\text { violistas relataram dor em cervical e ombro esquerdo. }\end{array}$ & 3 \\
\hline $\begin{array}{l}\text { Nyman T, } \\
\text { Wiktorin C, } \\
\text { Mulder M, } \\
\text { Johansson Y. } \\
\text { (2007) }\end{array}$ & $\begin{array}{l}235 \text { músicos } \\
\text { de orquestras } \\
\text { suecas. }\end{array}$ & $\begin{array}{l}\text { Responderam à um questionário. E foram } \\
\text { distribuídos em grupos: posição neutra de } \\
\text { braço }<2 \mathrm{hr} / \text { dia de trabalho; posição neutra } \\
\text { de braço >3 hr/dia de trabalho; posição de } \\
\text { braço elevado <2 hr/dia de trabalho; posição } \\
\text { de braço elevado >3 hr/dia de trabalho }\end{array}$ & $\begin{array}{l}25.5 \% \text { dos } 235 \text { músicos relataram dor cervical e de ombro. No grupo } \\
\text { correspondente a violino e viola } 35.3 \% \text { relataram dor cervical e de ombro. }\end{array}$ & 4 \\
\hline $\begin{array}{l}\text { Stechman Neto } \\
\text { et al (2009) }\end{array}$ & $\begin{array}{l}92 \text { músicos } \\
\text { (70 músicos } \\
\text { intérpretes de } \\
\text { instrumentos } \\
\text { de sopro e } \\
22 \text { músicos } \\
\text { intérpretes de } \\
\text { instrumentos de } \\
\text { cordas) }\end{array}$ & $\begin{array}{l}\text { Palestra explicativa sobre disfunções } \\
\text { temporomandibulares e entrevista. }\end{array}$ & $\begin{array}{l}\text { Dos39 músicos que relataram perceber que rangem e/ou apertam os } \\
\text { dentes, } 5 \text { músicos que são instrumentistas de cordas, viola e violino, } \\
\text { relataram a presença deste hábito enquanto estão tocando o instrumento. } \\
23 \text { músicos, sendo } 19 \text { e } 4 \text { intérpretes de instrumentos de sopro e corda, } \\
\text { respectivamente, disseram sentir dor na ATM. } 19 \text { músicos de ambos os } \\
\text { grupos relataram dificuldade para abrir a boca com maior amplitude. } 39 \\
\text { músicos relataram presença de ruídos na ATM, sendo que } 27 \text { pertencem } \\
\text { ao grupo dos instrumentistas de sopro e } 12 \text { de corda. }\end{array}$ & 4 \\
\hline
\end{tabular}


São fatores que predispõe ao adoecimento: o aumento súbito das sessões ao instrumento, o condicionamento físico inadequado, os hábitos errôneos na prática instrumental como a falta de aquecimento e alongamento musculares, as questões técnicas do instrumento como pegas com tensão e força excessiva, a troca de instrumento, a reabilitação inadequada de lesões prévias, as posturas e o uso inadequado do corpo. Questões de variabilidade anatômica individual e de gênero, o uso de cadeiras inapropriadas, a execução de atividades extras musicais que estressam a musculatura, a qualidade dos instrumentos utilizados, as condições ambientais, como baixa iluminação e temperatura, também são fatores relevantes. ${ }^{1,2,8,11}$

As trocas de repertório ou de instrumento também são fatores de risco. O repertório é considerado parâmetro crítico em relação aos níveis de força e pressão produzidos durante a performance, interagindo com os acessórios acrescentados ao instrumento, como a queixeira. $\mathrm{O}$ fator de risco mais influente, contudo, diz respeito ao aumento do tempo de uso do instrumento e de períodos de ensaio. , $^{1,8,11}$

Lesões musculoesqueléticas são definidas como um conjunto de afecções que podem acometer o sistema músculo-esquelético, isolada ou associada, com ou sem degeneração de tecidos, atingindo principalmente, membros superiores, região escapular e pescoço. ${ }^{13}$ Segundo Brito et al. ${ }^{14}$, essas lesões podem se apresentar sob várias formas, como afecções musculotendíneas, compressões nervosas ou disfunções motoras.

Os sintomas musculoesqueléticos podem variar desde desconforto e pode piorar e levar a lesões graves e consequente inabilidade e afastamento da profissão e também interrupção da rotina doméstica. ${ }^{15,16}$

Em um estudo retrospectivo para saber as razões pelas quais os músicos procuravam médicos ortopedistas no período de 1994 a 2001, Nourissat et al. ${ }^{17}$, verificaram que dois terços do total de 227 músicos apresentavam alguma desordem do sistema músculo-esquelético.

Em seu estudo, Andrade e Fonseca ${ }^{18}$ encontraram que o tipo de instrumento teve pouca influência na ocorrência de desconforto físico, mas a viola e o contrabaixo apresentaram maior proporção de indivíduos que tiveram que interromper a atividade instrumental. No entanto, estudos epidemiológicos encontram resultados muito divergentes quanto à prevalência geral de problemas num só instrumento: ora são os violinistas e violistas mais acometidos por problemas, ora estes apresentam menos sintomas. ${ }^{19}$

Um estudo que investigou disfunção temporomandibular em 92 músicos, sendo 22 violistas e violinistas, encontrou que $25 \%$ dos músicos tinham histórico de dor temporomandibular, sendo 18,18 instrumentistas de cordas. Estalos foram encontrados em $54,54 \%$ dos músicos de corda. ${ }^{20} \mathrm{O}$ posicionamento do pescoço e mandíbula no instrumento, a pressão excessiva para segurar o instrumento e oclusão com força excessiva, são as causas primárias da disfunção temporomandibular. Foram encontrados mais problemas nos violistas. Violinistas e violistas sintomáticos podem alterar sua técnica para reduzir a força causada pelo instrumento na mandíbula, reduzindo a dor e a disfunção. ${ }^{20,21}$

A coluna cervical também pode ser afetada devido à prolongada posição da cabeça e pescoço usada para segurar o instrumento. Posição essa que pode causar espasmo muscular e compressão nervosa. Tocar qualquer instrumento exige trabalho de precisão de mãos e dedos, o que requer atividade estabilizadora da musculatura da região do pescoço e ombro ${ }^{8,22-26}$.

No estudo de Nyman et al. ${ }^{22}$, houve prevalência de dor no pescoço e ombro de $35,3 \%$ no grupo contendo violistas e violinistas. Hagberg et al. ${ }^{9}$ encontraram que violistas e violinistas tem a incidência de dor no pescoço, ombro, cotovelo e antebraço maior quando comparados com pianistas.

O violino e a viola requerem uma posição extrema de rotação externa de ombro, elevação de braço e supinação máxima constante do antebraço esquerdo o que pode levar a bursite e tendinopatias dos músculos do ombro. A conseqüente carga sobre os tendões da musculatura adjacente ao ombro pode causar lesões por overuse, e deve ser considerado que a manutenção da elevação do braço aumenta a pressão intramuscular. ${ }^{19,22,26}$ Os violistas relatam mais dor em ombro e braços devido ao maior peso e tamanho da viola, comparada ao violino. ${ }^{27}$

Violinistas e violistas mostraram uma predominância em desordens no membro superior esquerdo como tendinite e síndromes compressivas. A mão esquerda de violinistas apresenta em torno de duas vezes mais problemas do que a mão direita, podendo ser isto derivado da posição mais dificultosa em que se encontram punho e dedos para exercer o trabalho de dedilhado. ${ }^{19}$ Os flexores e extensores da mão direita são usados para controlar o arco e os músculos que mantêm a mão esquerda em desvio ulnar assim como os extensores dos dedos também podem apresentar overuse..$^{8,12,19,21}$

A manutenção da postura sentada durante todo o período de prática, associada à postura técnica adotada pelo violinista e violista, representa fator considerável de desconforto para a realização da atividade, devido ao aumento do esforço muscular para a manutenção das posturas e à redução do fluxo sanguíneo, o que favorece o aparecimento de processos álgicos. ${ }^{6,22}$

As cadeiras, por não apresentarem dispositivos de ajustes, não oferecem outra opção senão a adaptação do corpo frente às exigências posturais que se colocam para tocar o violino. ${ }^{6}$

As questões posturais estavam associadas ao desconforto em pelo menos $90 \%$ dos músicos no estudo de Andrade e Fonseca. ${ }^{18}$ De acordo com Medoff e Hallberg ${ }^{28}$, os problemas mais comuns durante a postura sentada são o mau posicionamento dos pés, rotação pélvica, aumento da lordose lombar e sua rotação para a direita, retificação torácica, elevação de ombros e cotovelos, cabeça fletida e rodada para a esquerda.

O fato desses músicos, diariamente, ocuparem a mesma posição dentro do posto de trabalho condiciona a postura corporal no manuseio do instrumento e a direção do olhar para a partitura, sendo que a leitura da partitura é feita por duplas, e o maestro. Quando a posição é modificada, fazem-se necessárias modificações dos movimentos com o violino/viola e os ajustes no plano de visão para a leitura da partitura e a observação dos gestos do maestro. Esses ajustes geram exigências físicas nos arranjos posturais, especialmente porque essa troca na posição da fila não ocorre com frequência, o que impossibilita a automatização no uso do corpo. 6,22,27

O violinista/violista pratica em três ambientes diferentes, o salão de ensaio e no teatro, o palco e o fosso, sendo que o mobiliário do salão de ensaio é diferente do palco e do fosso o que exige adaptações de posicionamento da cadeira e da estante para meIhorar a visualização do maestro e da partitura. ${ }^{6,22}$

Segundo Ostwald ${ }^{8}$, redução do tempo de prática, aquecimento antes de tocar, incorporar períodos de descanso durante os treinos, correção de técnicas erradas, alimentação e hidratação adequada auxiliam na prevenção de lesões. Assim como informações adequadas para o músico, atitudes ergonômicas representadas por postura adequada em casa e no trabalho, utilização do mobiliário 
adequado, conscientização referente aos problemas posturais como forma de prevenção de doenças. ${ }^{29}$

Modificações da técnica errada, alterações dos hábitos de prática, períodos de descanso, treino de posturas corretas, alongamentos frequentes e uso de apoio para queixo e ombros auxiliam no tratamento de diversas alterações. 4,8,10,11

O uso de apoio para o queixo (queixeira) e de suporte na região do ombro, chamada espaldeira ou espaleira, em alturas adequadas podem aliviar o desconforto, mesmo que aumentem em até $20 \%$ o peso do instrumento. ${ }^{27}$

De acordo com o estudo de Levine e Irvine ${ }^{30}$, o biofeedback tem sido utilizado como forma de tratamento e prevenção, na tentativa de minimizar tensões desnecessárias, principalmente em violinistas. Para atingir destreza necessária para se tornar um músico de alto nível, são necessárias muitas horas de treinamento e aperfeiçoamento, o que pode levar anos de prática para que tal "perfeição" seja atingida. A prática excessiva pode predispor ao surgimento de lesões leves à graves.

\section{CONCLUSÃO}

O pescoço, ombro e a articulação temporomandibular são os mais afetados devido à posição prolongada de flexão da cabeça e ombro para segurar o violino, cotovelo e dedos também são alvos de desordens. É necessário alertar aos músicos de como são os sintomas iniciais para evitar que o distúrbio se agrave.

Como a prevenção é a melhor estratégia. Posturas incorretas, métodos incorretos e grande discrepância entre o tamanho do músico e violino devem ser evitados, e, se já existentes, corrigidos. Manutenção do instrumento e utilização adequada de mobiliário não devem ser esquecidas.

Na maioria dos estudos não são citadas as categorias específicas dos instrumentos musicais. Poucos estudos específicos sobre desordens musculoesqueléticas em violinistas e violistas foram encontrados, o que torna necessários mais estudos relacionados à essa população.

\section{REFERÊNCIAS}

1. Foxman I, Burgel BJ. Musician health and safety: Preventing playing-related musculoskeletal disorders. AAOHN J. 2006;54:309-16.

2. Zaza C, Farewell VT. Musicians' playing-related musculoskeletal disorders: an examination of risk factors. Am J Ind Med. 1997;32:292-300.

3. Zaza C. Playing-related musculoskeletal disorders in musicians: a systematic review of incidence and prevalence. CMAJ. 1998;158:1019-25.

4. Hoppmann RA, Patrone NA. A review of musculoskeletal problems in instrumental musicians. Semin Arthritis Rheum. 1989;19:117-26.

5. Schuele S, Lederman R. Occupational disorders in instrumental musicians. Med Probl Perform Art. 2004;19:123.

6. Petrus A. Produção musical e desgaste musculoesquelético: elementos condicionantes da carga de trabalho dos violinistas de uma orquestra [dissertação]. Belo Horizonte: Universidade Federal de Minas Gerais; 2005

7. Dawson WJ. Upper-extremity problems caused by playing specific instruments. Med Probl Perform Art. 2002; 17:135-40.

8. Lederman RJ. Neuromuscular and musculoskeletal problems in instrumental musicians. Muscle Nerve. 2003;27:549-61.

9. Hagberg M, Thiringer G, Brandström L. Incidence of tinnitus, impaired hearing and musculoskeletal disorders among students enrolled in academic music education: a retrospective cohort study. Int Arch Occup Environ Health. 2005; 78:575-83.

10. Fry HJ. The treatment of overuse syndrome in musicians. Results in 175 patients. J R Soc Med. 1988;81:572-5.

11. Ostwald PF, Baron BC, Byl NM, Wilson FR. Performing arts medicine. West J Med.1994;160:48-52

12. Liu S, Hayden GF. Maladies in musicians. South Med J. 2002;95:727-34.

13. Brasil. Secretaria de Políticas de Saúde. Departamento de Ações Programáticas e Estratégias. Protocolo de investigação, diagnóstico, tratamento e prevenção de lesões por esforços repetitivos distúrbios:osteomusculares relacionados ao trabalho. Brasília: Ministério da Saúde; 2000.32p.

14. Brito A, Orso M, Gomes E. Lesões por esforços repetitivos e outros acometimentos reumáticos em músicos profissionais. Rev Bras Reumatol. 1992;32:79-83
15. Amadio PC, Russotti GM. Evaluation and treatment of hand and wrist disorders in musicians. Hand Clin. 1990;6:405-16.

16. Ranney D. Distúrbios osteomusculares crônicos relacionados ao trabalho. São Paulo: Rocca; 2000. 344p.

17. Nourissat G, Chamagne P, Dumontier C. [Reasons why musicians consult hand surgeons]. Rev Chir Orthop Reparatrice Appar Mot. 2003;89:524-31.

18. Andrade EQ, Fonseca JGM. Artista-atleta: reflexões sobre a utilização do corpo na performance dos instrumentos de cordas. Per mus. 2000;2:118-28.

19. Frank A, Mühlen C. Queixas musculoesqueléticas em músicos: prevalência e fatores de risco. Rev Bras Reumatol. 2007;47:188-96.

20. Stechman Neto J, Almeida C, Bradasch ER, Corteletti LCBJ, Silvério KC, Pontes MMA, et al. Ocorrência de sinais e sintomas de disfunção temporomandibular em músicos. Rev Soc Bras Fonoaudiol. 2009;14:362-6.

21. Daum M. Occupational hazards in music. Disponível em: tigger.uic.edu/sph/ glakes/harts1/HARTS_library/musichaz.txt.

22. Nyman T, Wiktorin C, Mulder M, Johansson YL. Work postures and neck-shoulder pain among orchestra musicians. Am J Ind Med. 2007;50:370-6.

23. Lockwood AH. Medical problems of musicians. N Engl J Med. 1989;320:221-7.

24. Lederman RJ. AAEM minimonograph \#43: neuromuscular problems in the performing arts. Muscle Nerve. 1994;17:569-77.

25. Fedak K. String players injuries. Disponível em: www.musiciansclinic.com.

26. Abréu-Ramos AM, Micheo WF. Lifetime prevalence of upper-body musculoskeletal problems in a professional-level symphony orchestra: age, gender and instrument-specific results. Med Probl Perform Art. 2007;22:97.

27. Costa C.Quando tocar dói: análise ergonômica do trabalho de violistas de orquestra [dissertação]. Brasília: Universidade de Brasília UnB; 2003.

28. Medoff L, Hallberg K. Movement Training as an important factor in the training of the young violinist. Disponível em: http://www.uwsp.edu/cofac/suzuki/ AmericanSuzukilnstitute/Symposium/1997Abstracts.pdf.

29. Mendes RA, Leite N. Ginástica laboral: princípios e aplicações práticas. São Paulo: Manole; 2004. 208p.

30. LeVine WR, Irvine JK. In vivo EMG biofeedback in violin and viola pedagogy Biofeedback Self Regul. 1984;9:161-8. 